\section{Severe retinopathy of prematurity: longitudinal observation of disease and screening implications}

${ }^{1}$ Faculty of Medicine University of Calgary Calgary, Alberta, Canada

${ }^{2}$ Faculty of Medicine University of Calgary Department of Community and Health Sciences Calgary, Alberta, Canada

${ }^{3}$ The Alberta Children's Hospital

Department of

Ophthalmology

Calgary, Alberta, Canada

Correspondence: A Ells Alberta Children's Hospital 1820, Richmond Road SW Calgary, Alberta

Canada T2T 5C7

Tel + 14039437940

Fax: + 14039437672

Email: anna.ells@

calgaryhealthregion.ca

Received: 30 September 2003

Accepted: 6 January 2004 Published online: 25 June 2004
Abstract

Purpose To test the effectiveness of our Canadian retinopathy of prematurity (ROP) screening guidelines as applied to high-risk premature infants.

Study Design Retrospective longitudinal cohort study.

Subjects A total of 969 infants were examined longitudinally between 1991 and 2000 and 46 of these infants screened were treated for severe ROP.

Methods Data from weekly ROP screening examination results were collected from a geographical area and analysed.

Results The average incidence of severe ROP requiring treatment in the population of premature infants eligible for screening was 48.3 per 1000. In all, 46 infants were treated in this cohort. The mean gestational age (GA) was 25.5 weeks of age and the mean birth weight was $750 \mathrm{~g}$. The mean chronological age (CA) and postmenstrual age (PMA) at the time of first screening was 36 days and 30.7 weeks, respectively. The first identification of any ROP in this group was at a mean CA 60 days and PMA of 34.1 weeks. The mean CA and PMA of the first observation of stage 3 were 74 days and 36.3 weeks. The mean CA and PMA at the time of treatment were 86 days and 37.7 week.

Conclusions Our observations and analysis indicate the following ROP screening recommendations: infants of 28 weeks of GA or less, infants with a GA between 28 weeks and 30 weeks should have a single 'spot examination' at approximately 37 weeks of PMA (or prior to discharge from hospital) to include possible outliers; infants born with a

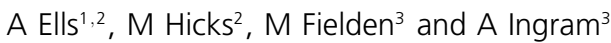

birth weight of $1250 \mathrm{~g}$ or less; initial screening examination should be at 31 weeks of PMA or 4 weeks of $\mathrm{CA}$, whichever is later; in the presence of any active ROP, the infant should be followed every 1-2 weeks; and stage 3 should be followed at least every 7 days. Eye (2005) 19, 138-144. doi:10.1038/sj.eye.6701437 Published online 25 June 2004

Keywords: severe retinopathy of prematurity (ROP); screening guidelines; revision; Canadian

Introduction

The primary objective of screening is to find disease at a time that is appropriate for intervention or treatment. This is particularly true when screening for retinopathy of prematurity (ROP) as there is clear evidence that treatment must be provided within a particular range of severity of the disease. ${ }^{1}$ Since validation by the collaborative Cryo-ROP study of the benefits of surgical intervention for severe ROP, guidelines for screening have been established in many countries. (Table 1). They vary with respect to the degree of prematurity as measured by gestational age (GA), birth weight, the timing of initial examination, and the frequency of subsequent examinations. The Canadian guidelines were established using available data and the agreement of individuals experienced with the recognition and treatment of ROP. ${ }^{2}$

We have tested the effectiveness of those guidelines as applied to the high-risk premature infants born in southern Alberta and southeastern British Columbia who were all 
Table 1 International ROP screening guidelines or recommendations

\begin{tabular}{|c|c|}
\hline Country & Screening Guidelines or Recommendations \\
\hline Chile & BW $<1750$ g or GA $<32$ weeks \\
\hline Brazil/Latin America & $\mathrm{BW}<1750 \mathrm{~g}$ or 30 days suppl $\mathrm{O}_{2}^{10}$ \\
\hline New Zealand & $\mathrm{BW}<1500 \mathrm{~g}$ or $\mathrm{GA} \leq 28$ weeks $^{11}$ \\
\hline Canada & $\mathrm{BW} \leq 1500 \mathrm{~g}$ or $\mathrm{GA} \leq 30$ weeks $^{12}$ \\
\hline United States & $\mathrm{BW}<1500 \mathrm{~g}$ or $\mathrm{GA} \leq 28$ weeks $^{13}$ \\
\hline United Kingdom & $\mathrm{BW} \leq 1500 \mathrm{~g}$ or $\mathrm{GA} \leq 31$ weeks $^{14}$ \\
\hline Iran & $\mathrm{BW}<1500 \mathrm{~g}$ or $\mathrm{GA}<32$ weeks $^{15}$ \\
\hline India & $\mathrm{BW} \leq 1250 \mathrm{~g}$ and $\mathrm{GA} \leq 32$ weeks $^{16}$ \\
\hline Singapore & $\mathrm{BW}<1250 \mathrm{~g}$ or $\mathrm{GA}<32$ weeks $^{17}$ \\
\hline Saudi Arabia & $\mathrm{BW}<1500 \mathrm{~g}^{18}$ \\
\hline Slovenia & $\mathrm{BW} \leq 1500 \mathrm{~g}$ and $\mathrm{GA} \leq 30$ weeks $^{19}$ \\
\hline Sweden & $\mathrm{GA} \leq 31$ weeks $^{20}$ \\
\hline Spain & $\mathrm{BW} \leq 1250 \mathrm{~g}$ or $\mathrm{GA} \leq 30$ weeks $^{21}$ \\
\hline Japan & $\mathrm{BW}<1500 \mathrm{~g}$ and $<31$ weeks $^{22}$ \\
\hline Taiwan & $\mathrm{BW} \leq 1500 \mathrm{~g}$ or $\mathrm{GA} \leq 31$ weeks $^{23}$ \\
\hline
\end{tabular}

${ }^{*}$ Exceptions are made to infants outside the guidelines with an unstable clinical course in most recommendations.

attended in the tertiary level intensive care units within the Calgary Health Region. We have examined all data on the development of ROP in those infants that required treatment over a 10-year period looking for evidence that the guidelines were accomplishing the objective of timely recognition of serious vision-threatening ROP.

\section{Methods}

\section{Study design}

The study was approved by the Child Health Research Unit of the Alberta Children's hospital and the University of Calgary Ethics Review Board. The inpatient and outpatient records of all infants who were treated for severe ROP in the Calgary Health Region from 1991 to 2000 were reviewed. Patient demographics, dates of each examination, and results were recorded for all infants in this 10-year period.

\section{Screening criteria}

Examinations were carried out according to the Canadian Screening Guidelines for ROP as follows: infants born with a GA of 30 weeks or less; and a birth weight of $1500 \mathrm{~g}$ or less or at the discretion of the attending neonatologist. $^{2}$

The first ROP examination was performed between 4 and 6 weeks of chronological age (CA) by four paediatric ophthalmologists. Subsequent examinations were scheduled at 2-week intervals if no ROP was present and weekly if ROP was detected. ${ }^{3}$

\section{Clinical examinations}

The infants' pupils were dilated with a combination of $0.2 \%$. cyclopentolate and $1.0 \%$ phenylephrine drops, topically administered $45-60 \mathrm{~min}$ prior to the scheduled examination and repeated. Topical proparicaine $(0.5 \%)$ was applied immediately before the examination. Indirect ophthalmoscopy and/or direct ophthalmoscopy through an infant gonioscopy lens of the entire retina was performed. The quality and quantity of ROP was recorded according to the International Classification of ROP. ${ }^{4}$ Prior examination results were routinely observed, which enabled the identification of change as well as detecting possible error with the former or current examination results. Thorough comparison and discussion over the years prior to the study assured interobserver reliability, particularly with respect to the identification of stage 3 ROP.

\section{Follow-up examinations}

All infants in the geographic study area who had serious ROP and any who developed visual disability or blindness from ROP become known to the paediatric ophthalmologists at the Eye clinic and the Perinatal follow-up clinic of the Alberta Children's Hospital.

\section{Definition of terms}

GA: By convention, GA refers to weeks since the onset of the last menstrual period to the time of birth, with 40 weeks of GA considered to be full term. Accordingly, the actual gestation is approximately 38 weeks for a term birth. Although incorrect, it is not our desire to alter that historic convention. The assigned GA for any premature infant is based upon the best estimation by the attending obstetrician and perinatologists supported by history, last menstrual period, ultrasound, and the Ballard or Dubowitz score. ${ }^{5}$

Chronological age: Age since birth to the particular event in days or weeks.

Postmenstrual age: This term is used to maintain consistency with GA and represents the number of weeks from birth, adjusted according to the GA.

\section{Data handling}

The data were entered in Microsoft Excel in duplicate. All statistical analyses were carried out with Intercooled Stata Version 6.0 (College Station, TX, USA) (68). All tests were two-sided (where applicable), and significance was defined as $P$-value $<0.05$. Univariate descriptive statistics were used to identify potential data entry errors and characterize subjects. Continuous variables were 
described in terms of mean, median, range, standard deviation, skewness, and quartiles. Histograms, stemleaf, and box plots were generated to evaluate assumptions of normality and to detect outlying values. Bivariate analysis was used to examine characteristics of subjects. Statistical analyses were performed by Student's $t$-test for continuous variables and $\chi^{2}$-test for categorical variables.

\section{Results}

\section{Patients}

From 1991 to 2000, 969 premature infants from the Calgary Health Region who survived to 6 weeks of age, became eligible for an ROP screening examination according to our guidelines. The incidence of severe ROP requiring treatment among survivors with a birth weight of $<1240 \mathrm{~g}$, for each year of the study is listed in Table 2 . The average incidence was 48.3 per 1000. In all, 46 infants (29 males and 17 females) were treated for severe ROP during this time period. In all, 15 infants within the cohort were non-Caucasian (one African-American, three of Chinese descent, three Filipino, five from East India, and three native Canadians). During this study period, no infants from our perinatal follow-up clinic were discovered to have evidence of visually disabling cicatricial disease that had not been treated for ROP.

\section{Patient characteristics}

The general mean characteristics of these infants were as follows: mean GA 25.5. weeks (range 24-31 weeks, Figure 1) with no statistical significance between males and females; and mean birth weight $750 \mathrm{~g}$ (range 471$1240 \mathrm{~g}$ ). There was a statistical significance between males and females with regard to their birth weights $(P=0.0392)$. The mean birth weight for male infants was 800 and $680 \mathrm{~g}$ for the females. No infant with a birth weight greater than $1240 \mathrm{~g}$ was treated for ROP within the study period. Table 3 reports the general characteristics of prematurity of this group.

The mean CA and postmenstrual age (PMA) at the time of the first screening examination was 36 days

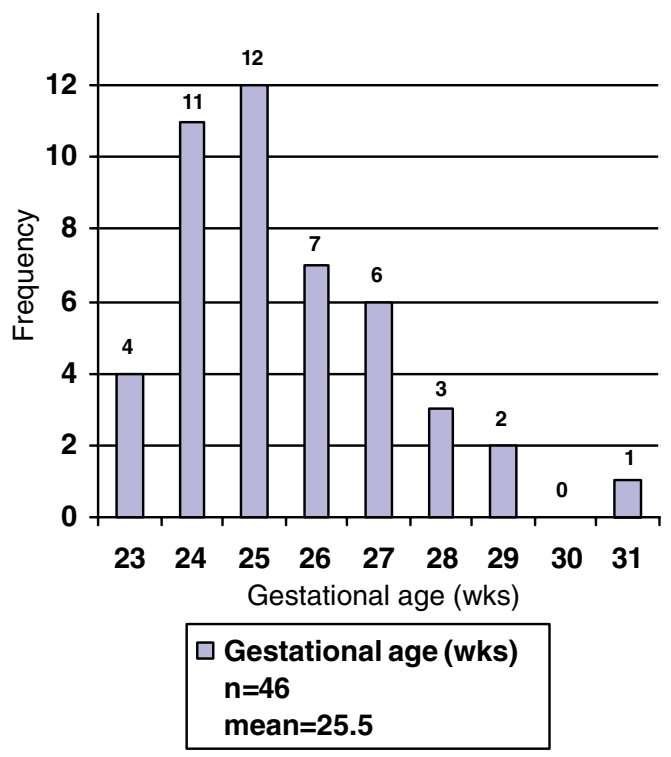

Figure 1 Frequency of GA of infants.

(range: 20-86 days) and 30.7 weeks (range: 26.9-37.3 weeks), respectively (Table 4). The first identification of any $\mathrm{ROP}$ was at a mean chronological of 60 days (range 27-114 days) or a mean PMA of 34.1 weeks (range: 29.942.3 weeks). The mean CA and PMA at the time of the first observation of any stage 3 ROP were 74 days (range 27-114 days) and 36.3 weeks (range: $31.4-42.3$ weeks), respectively. The mean CA and PMA at the time of treatment were 86 days (range: $31-138$ days) and 37.7 weeks (range: $32.4-44$ weeks), respectively (Table 5).

\section{Discussion}

It is considered fundamental that ROP screening guidelines should ensure that all potential infants requiring treatment be captured by the criteria of birth weight and/or GA. Screening has become of even greater importance in the last 10 years as the parameter of 'success' in ROP management is prevention of visual disability as compared to preventing legal blindness.

Since the location, extent, and stage of ROP have been meticulously documented in our neonatal nurseries since

Table 2 Birth characteristics

\begin{tabular}{llllllclc}
\hline Variable & Category & $n$ & Mean & SD & Range & Median & Test & P-value \\
\hline Birthweight (g) & Total & 46 & 751.07 & 198.4 & $471-1240$ & 720 & & NA \\
& Male & 27 & 801.3 & 199.5 & $482-1240$ & 790 & Equal var, $t$-test two sides & 0.0392 \\
& Female & 19 & 679.7 & 178.2 & $471-1160$ & 650 & & NA \\
GA (weeks) & Total & 46 & 25.5 & 1.77 & $23-31$ & 25 & NA & 0.1095 \\
& Male & 27 & 25.8 & 1.85 & $24-31$ & 25 & Equal var, $t$-test two sides \\
& Female & 19 & 25.0 & 1.56 & $23-28$ & 25 & & \\
\hline
\end{tabular}


Table 3 CA and PMA at the time of first observation of any ROP

\begin{tabular}{|c|c|c|c|c|c|c|c|c|}
\hline Event & Variable & Category & $n$ & Mean & $S D$ & Range & Median & P-value \\
\hline \multirow[t]{10}{*}{ First observation of any ROP } & \multirow[t]{3}{*}{ CA (days) } & Total & 46 & 59.9 & 18.3 & $27-114$ & 56 & NA \\
\hline & & Male & 27 & 55.4 & 18.1 & $27-112$ & 52 & 0.10 \\
\hline & & Female & 19 & 65.2 & 18.3 & $40-114$ & 59 & \\
\hline & \multirow[t]{3}{*}{ PMA (weeks) } & Total & 46 & 34.1 & 2.4 & $29.9-42.3$ & 34.1 & NA \\
\hline & & Male & 27 & 33.9 & 2.1 & $30.4-41$ & 33.7 & 0.11 \\
\hline & & Female & 19 & 34.3 & 2.8 & $29.9-42.3$ & 34.4 & \\
\hline & & 0 & 88 & 2.8 & 3.91 & $0-11$ & 0 & \\
\hline & \multirow{3}{*}{ (clock hours) } & 1 & 88 & 4.6 & 4.29 & $0-12$ & 3 & \\
\hline & & 2 & 88 & 3.3 & 4.20 & $0-12$ & 1 & \\
\hline & & 3 & 88 & 0.9 & 2.58 & $0-12$ & 0 & \\
\hline
\end{tabular}

Table 4 CA and PMA data to time of first observation of any stage 3 ROP

\begin{tabular}{|c|c|c|c|c|c|c|c|c|}
\hline Event & Variable & Category & $n$ & Mean & $S D$ & Range & Median & P-value \\
\hline \multirow[t]{10}{*}{ First observation of Stage 3 ROP } & \multirow[t]{3}{*}{ CA (days) } & Total & 46 & 74.5 & 18.4 & $27-114$ & 75.5 & NA \\
\hline & & Male & 27 & 72.0 & 20.7 & $27-114$ & 74 & 0.30 \\
\hline & & Female & 19 & 77.9 & 14.9 & 54-114 & 77 & \\
\hline & \multirow[t]{3}{*}{ PMA (weeks) } & Total & 46 & 36.3 & 2.7 & $31.4-42.3$ & 36 & NA \\
\hline & & Male & 27 & 36.2 & 2.4 & $32.4-41$ & 35.6 & 0.54 \\
\hline & & Female & 19 & 36.4 & 2.7 & $31.4-42.3$ & 36.1 & \\
\hline & \multirow{4}{*}{$\begin{array}{l}\text { Stage } \\
\text { (clock hours) }\end{array}$} & 0 & 86 & 0.38 & 1.30 & $0-7$ & 0 & \\
\hline & & 1 & 86 & 1.79 & 2.70 & $0-9$ & 0 & \\
\hline & & 2 & 86 & 6.15 & 3.27 & $0-11$ & 6 & \\
\hline & & 3 & 86 & 3.62 & 2.68 & $1-12$ & 3 & \\
\hline
\end{tabular}

Table 5 CA and PMA data to time of first treatment

\begin{tabular}{lllllllcc}
\hline Event & Variable & Category & $n$ & Mean & SD & Range & Median & P-value \\
\hline First treatment & CA (days) & Total & 45 & 86.4 & 20.7 & $31-138$ & 85 & NA \\
& & Male & 26 & 87.8 & 24.2 & $31-138$ & 85 & 0.56 \\
& \multirow{3}{*}{ PMA (weeks) } & Female & 19 & 84.3 & 14.7 & $56-114$ & 85 & NA \\
& & Total & 44 & 37.7 & 2.8 & $32.4-44$ & 37.6 & 38.2 \\
& Male & 26 & 38.3 & 2.9 & $32.6-44$ & 0.047 \\
& Female & 18 & 36.9 & 2.6 & $32.4-42$ & 36.8 & \\
\hline
\end{tabular}

1981, at intervals from a maximum of 2 weeks to a minimum of 1 day, the data set was reliably poised to test our Canadian guidelines.

\section{Is the guideline for screening all infants with a GA 30 weeks or less valid?}

Study infants requiring surgical intervention for severe ROP were born from 23 to 31 weeks of gestation. The single infant born at 31 weeks would have been missed if GA was the sole criterion for screening. Accordingly, this guideline would fail on that parameter alone.

Fortunately, this infant qualified for screening on the basis of birth weight (infant's birth weight was $970 \mathrm{~g}$ ). Additionally, the neonatologists were concerned as the infant had a particularly difficult course following intrauterine growth retardation. This outlier highlights the importance of the screening caveat from the attending neonatologists. Considering our entire cohort, other than this outlier, all other infants had a GA of 28 weeks and less.

\section{Is the guideline for screening all infants with birth weight of $1500 \mathrm{~g}$ or less valid?}

The range of birth weights of those treated infants was 471-1240 g. No infant weighing more than $1240 \mathrm{~g}$ at birth developed treatable stage 3 ROP in our geographical region during the study period. Although our study cohort does not include those infants who may have had 
stage 3 disease and not required treatment, from our follow-up data, we have no infants with significant visual disabilities who did not require treatment.

Additional Canadian evidence-based literature supports lowering the birth weight criteria. Lee et $\mathrm{l}^{6}$ published data collected from 14 intensive care nurseries across Canada supporting screening only those infants having a birth weight of $1200 \mathrm{~g}$ or less. This study included 16, 424 premature infants, in which all but one treated patient (GA of 32 weeks and birth weight of $1785 \mathrm{~g}$ ) had a birth weight less than $1200 \mathrm{~g}$. Reducing the birth weight criteria from $1500 \mathrm{~g}$ to $1200 \mathrm{~g}$ reduced the number of infants screened by $46 \%$ and was the most cost-effective strategy, reducing the screening cost by approximately 1 million Canadian dollars per year. Also suggested by the authors was a single screening examination at 37 weeks PMA for those infants with a birth weight from 1200 to $1800 \mathrm{~g}$, to include possible outliers. Our study data and data from the Cryo-ROP study $^{7}$ also support a 'spot exam' at 37 weeks PMA. This examination could also occur just prior to discharge, as close to 37 weeks of PMA as possible, to prevent loss to follow-up. In both cohorts, the mean PMA at the time of treatment was 37 weeks; therefore, a 'spot examinations' in this time period of infant's at lower risk would potentially capture outliers in need of treatment in a timely manner. This strategy would minimize the frequency of examinations for those infants at very low risk for severe disease.

\section{When should the first examination occur?}

The first observation of stage $3 \mathrm{ROP}$ in our cohort had a range of 27-114 days from birth. The CA at treatment ranged from 31 to 138 days. These data would suggest that the first examination for ROP should be within 27-31 days of chronological age. Given that examinations were performed once every 7 days in the presence of any observed ROP, stage 3 ROP could have developed at any time after the preceding examination that had less or no ROP. In addition, no treated infants were observed to have stage 3 before 31.4 weeks of PMA. The earliest PMA at which treatment was considered necessary was 32.4 weeks (range 32.4-44 weeks). These data support the first ROP examination at 31 weeks of PMA to catch the earliest possible stage 3 disease.

The first examination at 4 weeks chronologic age or 31 weeks PMA, whichever is the later, would capture all at risk in our study group. By adjusting the timing of the initial examination, not only are the overall amount of screening examinations reduced but those youngest, smallest infants can be spared examinations at times when they are more fragile and more likely to have an adverse systemic response to the examination. For
Table 6 Recommended timing of initial ROP screening examination

\begin{tabular}{ll}
\hline$G A$ & Timing of first exam \\
\hline 23 weeks & 31 weeks of PMA \\
24 weeks & 31 weeks of PMA \\
25 weeks & 31 weeks of PMA \\
26 weeks & 31 weeks of PMA \\
27 weeks & 31 weeks of PMA and/or 4 weeks of \\
& chronological age \\
28 weeks & 4 weeks of chronological age \\
29 weeks & 37 weeks of PMA \\
30 weeks & 37 weeks of PMA \\
\hline
\end{tabular}

example; an infant born at a GA of 25 weeks should have the first ROP examination at 31 weeks PMA; not 28 days of life: an infant born at 26 weeks of GA should have the first examination at 31 weeks of PMA: an infant born at 27 weeks of GA should have the first examination at 31 weeks of PMA: and so on (Table 6).

Our results correspond almost exactly with those published Reynolds et al. ${ }^{8}$ This recent study presents data analysis from two prospective randomized trials (CryoROP study and Light Reduction in ROP Study) with an objective to define evidence-based criteria for ROP screening examinations. They conclude that the initial examination should occur at 31 weeks of PMA or 4 weeks' of chronological age, whichever is later.

\section{Is the examination interval of 2 weeks appropriate if the prior examination showed no ROP?}

The shortest interval between first observation of any ROP and first observation of stage 3 ROP was zero days, as this particular infant had stage 3 present on the first examination. Therefore, the shortest interval at which any infant required treatment after a negative examination was also 0 days. This infant was an outlier. The mean value for interval between first observation of any ROP and treatment date was 12 days. This suggests that in the presence of any ROP on a particular screening examination, the greatest interval between subsequent examinations should not exceed 2 weeks during the active phase of ROP. As the stage and extent of ROP increases at each examination, the interval between visits should correspondingly decrease at the discretion of the examining ophthalmologist. This concept is also supported by data from the Cryo-ROP study. ${ }^{7,9}$

\section{Do we have evidence to support weekly examinations, in the presence of any ROP?}

In our study, the shortest interval where treatment was applied after stage 3 was first observed was 3 days, which occurred in a patient born with a GA of 31 weeks, 
birth weight of $970 \mathrm{~g}$ and stage 3 observed on the first ROP screening examination at 28 days of life. In the Cryo-ROP study, the median time from onset of pre threshold to onset of threshold disease did not exceed 1 week for each of the three sub-groups divided by birthweight. $^{7}$

\section{Long term follow-up}

We have not analysed our data on this point. The recommendations of performing screening examinations until the retina is fully vascularized or all ROP has resolved appeal to reason in order that the internal state of the eye be known for future reference. This certainly applies to the recommendation that any infant with ROP should be examined within 6 months of their expected full-term birth.

\section{Conclusion}

Our observations and analysis and existing published literature indicate that at least in our geographic area, premature infants should be examined according to the following guidelines:

1. Infants of 28 weeks gestation or less.

2. Infants with a GA between 28 and 30 weeks should have a single 'spot examination' at approximately 37 weeks of PMA age, to include possible outliers. If follow-up logistics pose difficulties, this 'spot examination' should occur just prior to discharge from the nursery.

3. Infants born with a birth weight of $1250 \mathrm{~g}$ or less.

4. The initial examination should be at 31 weeks of PMA age or 4 weeks of chronological age, whichever is later.

5. If no ROP is present, the examination should be repeated approximately every 2 weeks until vascularization is fully into zone III.

6. If there is any ROP, the infant should be followed every 1-2 weeks until it is evident that the ROP is resolving and vascularization is into zone III.

7. Stage 3 ROP should be followed at least every 7 days or more frequently at the discretion of an ophthalmologist fully experienced with ROP and its treatment.

Revision of existing guidelines for most countries, according to our recommendations, would allow fewer examinations of the smallest infants, decrease manpower demands on screening physicians, and result in savings to our health-care systems.

\section{Acknowledgements}

We wish to acknowledge Drs S Rose, R Sauve, and W Hindle for statistical and data support.

\section{References}

1 Cryotherapy for Retinopathy of Prematurity Cooperative Group. The natural ocular outcome of premature birth and retinopathy. Arch Ophthalmol 1994; 112: 903-912.

2 Canadian Association of Pediatric Ophthalmologists Ad Hoc Committee on Standards of Screening Examination for Retinopathy of Prematurity. Guidelines for screening examinations for retinopathy of prematurity. Can J Ophthalmol 2000; 35(5): 251-252.

3 Ells A, Hindle W. Commentary on guideines for screening for retinopathy of prematurity. Can J Ophthalmol 2000; 35(5): 253-254.

4 The Committee for the Classification of Retinopathy of Prematurity. An international classification of retinopathy of prematurity. Arch of Ophthalmol 1984; 102: 1130-1134.

5 Venes D (ed). Taber's Cyclopedic Medical Dictionary, 19 ed. F.A. Davis Company: Philadelphia, 2001.

6 Lee S, Normand C, McMillan D, Ohlsson A, Vincer M, Lyons C. Evidence for changing guidelines for routine screening for retinopathy of prematurity. Arch Pediatr Adolesc Med 2001; 155(3): 387-395.

7 Palmer E, Flynn J, Hardy R, Phelps D, Phillips C, Schaffer D et al. Incidence and early course of retinopathy of prematurity. Ophthalmology 1991; 98(11): 1628-1638.

8 Reynolds JD, Dobson V, Quinn GE, Fielder AR, Palmer EA, Saunders RA et al. Evidence-based screening criteria for retinopathy of prematurity. Arch Ophthalmol 2002; 120: 1470-1476.

9 Hardy RJ, Palmer EA, Schaffer DB, Phelps DL, Davis BR, Cooper CJ. Outcome-based management of retinopathy of prematurity. J AAPOS 1997; 1(1): 46-54.

10 Zin A. The increasing problem of retinopathy or prematurity. J Community Eye Health 2001; 40(3): http:// www.jceh.co.uk/journal/40_3.asp

11 Board ADH. Newborn Services Medical Guidelines Retinopathy of Prematurity. Auckland District Health Board, Auckland, New Zealand 2002.

12 Fetus and Newborn Committee CPS. Retinopathy of prematurity: A systematic review of the literature. Paediatr Child Health 1998; 3(3): 173-179.

13 American Academy of Pediatrics. Screening examination of premature infants for retinopathy of prematurity. Pediatrics 2001; 108(3): 809-811.

14 Retinopathy of prematurity: guidelines for screening and treatment. The report of a joint working party of the royal college of ophthlamologists and the British association of perinatal medicine. Early Hum Dev 1996; 46(3): 239-258.

15 Riazi Esfahani M, Karkhaneh R, Shokravi N. Assessment of retinopathy of prematurity among 150 premature neonates in Farabi eye hospital. Acta Med Iran 2001; 39(1): 35-38.

16 Sharma S, Kelgeri C, Avasthi BS. Retinopathy of prematurity. Indian Pediatr 2002; 39: 267-270.

17 See JLS, Wong TY, Yeo KT. Trends in the Pattern of Blindness and Major Ocular Diseases in Singapore and Asia. Ann Acad Med 1998; 27: 540-546. 
18 Al-Amro SA, Al-Kharfi TM, Thabit AA, Al-Mofada SM. Retinopathy of prematurity at a university hospital in Riyadh, Saudi Arabia. Saudi Med J 2003; 24(7): 720-724.

19 Stirn-Kranjc B, Kornhauser-Cerar L. Visual outsome in preterm infants - analysis of preterm infants born in Ljubljana 1990-1999. Zdrav Vestn 2001; 71(Supl. II): 105-108.

20 Larsson E, Holmstrom G. Screening for retinopathy of prematurity: evaluation and modification of guidelines. $\mathrm{Br} J$ Ophthalmol 2002; 86(12): 1399-1402.
21 Cruz Bertolo FJ, Pallas Alonso CR, Tejada Palacios P. Cribado para la retinopatia de la prematuridad: ni son todos los que estan, ni estan todos los que son. Anales espanoles de Pediatria 1999; 50(2): 156-160.

22 Ikeda N, Hayasaka S, Yano H, Kadoi C, Matsumoto M, Imamura $\mathrm{H}$ et al. Retinopathy of prematurity in Toyama area of Japan. Ann Ophthalmol 2001; 33(4): 303-308.

23 Chiang MC, Tang JR, Yau KI, Yang CM. A proposal of screening guidelines for retinopathy of prematurity in Taiwan. Acta Paediatric Taiwan 2002; 43(4): 204-207. 